\title{
TEORIA DE ESTADO E POLÍTICAS PÚBLICAS SOCIAIS: UM ESTUDO SOBRE A INFLUÊNCIA DO PENSAMENTO NEOLIBERAL NOS RUMOS TOMADOS PELA EDUCAÇÃO BRASILEIRA A PARTIR DA DÉCADA DE 1990
}

\author{
Débora Alfaro São Martinho da Silva \\ UFSCar
}

\begin{abstract}
RESUMO
As mudanças estruturais de ordem econômica e política ocorridas na última década do século XX em âmbito internacional levaram o Brasil a adaptar-se e aderir à nova lógica capitalista, reestruturada segundo o paradigma da ideologia neoliberal, para fazer parte da economia mundial. A alteração e a adequação de sua economia à nova ordem mundial implicaram, no entanto, a reforma do Estado e de suas instituições, dentre elas: a educacional. Esta reestruturação se desenvolveu sob a tutela de agências internacionais reguladoras, cuja atuação desenvolveu-se no sentido de monitoramento e intervenção nos processos de ajustes estruturais no país, subordinando estes à obtenção de financiamentos. $\mathrm{Na}$ educação, as consequências desta intervenção incidiram tanto na esfera ideológica, com a elaboração de documentos norteadores do rumo da educação, como em termos legais, onde foi preciso construir uma estrutura jurídica para imprimir os fundamentos do modelo neoliberal. Com o intuito de compreender a ressonância da teoria de estado neoliberal no âmbito educacional no Brasil, este artigo se propõe a revisitar os escritos dos precursores desta vertente a fim de verificar como seus princípios foram incorporados à reforma educacional promovida na década de 1990.

Palavras-chave: Neoliberalismo. Políticas educacionais. Educação brasileira.
\end{abstract}

\section{THEORY OF STATE AND POLITICAL PUBLIC SOCIAL: A STUDY ON THE INFLUENCE OF THE NEOLIBERAL THOUGHT IN THE BRAZILIAN EDUCATION IN THE 1990s}

\begin{abstract}
The international economic and political changes in 1990s forced Brazil to adapt itself to the new capitalism logic, according to neoliberal ideology pattern, to become part of word wide economy. The change and adaptation its economy to the new rules also changed the state and its institutions such as educational institutions. The development of such changes were performed under the tutelage of international agencies which their actions were the monitoring and intervention of processes related to the country adjustments made when financial resources were available. This intervention in education caused consequences to ideological trends, by the creation of documents to give good directions to educational system, as well juridical terms that were created as the basis of the fundaments of neoliberal model. To better understand the results of neoliberal state theory in the Brazil's educational system, this paper brings ideas and concepts from initial defenders of such political and economic rules to verify how its main ideas were laid down the educational reform in the 1990s.
\end{abstract}

Keywords: Neoliberalism. Education policies. Brazilian education. 
Nenhum modo de pensamento se torna dominante sem propor um aparato conceitual que mobilize nossas sensações e nossos instintos, nossos valores e nossos desejos, assim como as possibilidades inerentes ao mundo social que habitamos. Se bem-sucedidos, esse aparato conceitual se incorpora a tal ponto ao senso comum que passa a ser tido por certo e livre de questionamentos (HARVEY, 2013, p. 15).

\section{Neoliberalismo: origem e fundamentos}

Os primeiros ensaios da teoria neoliberal surgem na região da Europa e da América do Norte no período da Segunda Guerra Mundial. Nascem como uma reação teórica e política contra o modelo econômico keynesiano, alicerçado no Estado centralizador de bem-estar social, com capacidade de intervenção na economia e nos investimentos de recursos em políticas públicas sociais para garantir a seguridade social e a socialdemocracia. Seu texto de origem, $O$ caminho para a servidão, é escrito em 1944, pelo economista austríaco Friedrich August Von Hayek. Nesta obra, o autor defende que a fomentação deste Estado centralizador, intervencionista e coletivista, promotor de igualdade e justiça social conduziria a regimes totalitários, como: a Itália fascista, a Alemanha nazista e a Rússia socialista, servindo de ameaça à liberdade, não somente econômica, mas também, política. (HAYEK, 2013).

Milton Friedman (1988, p. 51), importante expoente norte-americano do neoliberalismo, escritor da obra de referência denominada Capitalismo e Liberdade, argumentava que a grande ameaça à liberdade está constituída pela concentração de poder. Ao concentrar o poder político para arbitrar sobre as atividades econômicas dos indivíduos, o Estado, de instrumento de preservação e promoção do exercício da liberdade, se constituiria em uma ameaça a esta. A tendência de dirigir toda a atividade econômica demandaria do Estado à criação de uma economia planificada, com a imposição de regras fixas, restrições coercitivas, padrões de atividades e uniformidade, levando os indivíduos a renunciarem a liberdade e se submeterem a prescrições coletivistas. Em nome do bem-estar e da igualdade, as políticas de intervenção estatal e o paternalismo substituiriam a utilização das forças espontâneas individuais encontradas numa sociedade livre e o mecanismo anônimo e impessoal do mercado pela "condução coletiva e 'consciente' de todas as forças sociais em direção a objetivos deliberadamente escolhidos".

Uma sociedade que preze a liberdade, afirmava Friedman (1988, p. 11), não pode se pautar em "uma visão que contraria a crença do homem livre em sua própria responsabilidade com relação a seu próprio destino". O Governo não pode ser visto como um protetor ou algo acima do indivíduo e o indivíduo, um ente coercitivamente tutelado. Para o homem livre, o Governo não pode ser compreendido como um distribuidor de favores e doações, nem como um senhor ou um Deus para ser cegamente servido e idolatrado, mas como um meio, um instrumento, para ajudá-lo a tomar as responsabilidades, a alcançar seus propósitos e objetivos diversos e, acima de tudo, a proteger sua liberdade. O verdadeiro significado da liberdade política, afirmava o autor, está na ausência de coerção dos indivíduos por parte de seus semelhantes. Sua preservação demandaria, pois, "a maior eliminação possível de [...] concentração de poder e a dispersão 
e a distribuição de todo o poder que não puder ser eliminado" (FRIEDMAN, 1988, p. 23). "Vista como um meio para a obtenção da liberdade política, a organização econômica é importante devido ao seu efeito na concentração ou dispersão do poder" (FRIEDMAN, 1988, p. 18). O tipo de organização econômica que promove a liberdade econômica, isto é, o capitalismo competitivo, promove também a liberdade política, porque separa o poder econômico do poder político, permitindo que um controle o outro.

A doutrina liberal é a favor da empresa privada e do mercado livre para que os indivíduos possam realizar trocas voluntárias convenientes sem a intervenção, o controle e o poder arbitrário do Estado; e do emprego das forças de concorrência, concebida como um meio capaz de coordenar os esforços humanos, ajustando as atividades dos indivíduos "umas às outras sem a intervenção coercitiva ou arbitrária da autoridade" e oferecendo a estes a "oportunidade de decidir se as perspectivas de desvantagens e riscos são suficientes para compensar as desvantagens e riscos que a acompanham" (HAYEK, 2013, p. 67).

De acordo com Friedman (1988, p. 23), a existência de um mercado livre não eliminaria, contudo, a necessidade de um governo: sendo impossível ao mercado criar condições para tornar efetivo o funcionamento apropriado da concorrência, seria preciso recorrer a outros métodos capazes de orientar a atividade econômica, como por exemplo, ao controle direto da autoridade do Estado. Recorrer ao Estado não significa, porém, suprimir a concorrência nos setores em que se possa fazê-la funcionar adequadamente, mas criar uma estrutura de funcionamento adequado e benéfico à concorrência, garantindo-lhe a atividade legal imprescindível para seu funcionamento eficiente e lhe completando a ação quando ela não possa ser, mediante o fornecimento de serviços em setores de bem-estar social, que não oferecem vantagens em termos de lucratividade do mercado, mas que embora lhe são necessários. Nas palavras de Adam Smith, serviços que "embora ofereçam as maiores vantagens para a sociedade, são, contudo, de tal natureza que o lucro jamais compensaria os gastos de um qualquer indivíduo ou pequeno grupo de indivíduos" (apud Hayek, 2013, p. 70). Estas tarefas ofereceriam "um campo vasto e indisputável para a atividade estatal", uma vez que "em nenhum sistema racionalmente defensável seria possível o Estado ficar sem qualquer função" (HAYEK, 1013, p. 70).

Um sistema eficaz de concorrência necessita, como qualquer outro, além do fornecimento de uma estrutura monetária adequada, uma estrutura legal cuidadosamente elaborada e sempre aperfeiçoada, capaz de "manter a lei e a ordem para evitar a coerção de um indivíduo sobre o outro; a execução de contratos voluntariamente estabelecidos; a definição do significado de direitos de propriedade, a sua interpretação e a sua execução" (FRIEDMAN, 1988, p. 35) e de uma concorrência "produzindo os resultados mais benéficos possíveis" (HAYEK, 2013, p. 63).

A existência de um mercado livre não elimina, evidentemente, a necessidade de um governo. Ao contrário, um governo é essencial para a determinação das 'regras do jogo' e um árbitro para interpretar e por em vigor as regras estabelecidas. $\mathrm{O}$ que o mercado faz é reduzir sensivelmente o número de questões que devem ser decididas por meios políticos - e, por isso, minimizar a extensão em que o governo tem que participar diretamente do jogo. $\mathrm{O}$ aspecto característico da ação política é o de exigir ou reforçar uma conformidade substancial. A grande vantagem do mercado, de outro lado, é permitir uma grande diversidade, significando, em termos políticos, um sistema de representação proporcional. [...] Esta é a característica do mercado para garantir a liberdade econômica, mas que também tem implicações que vão além desta (FRIEDMAN, 1988, p. 23). 
Onde não haja mercado, cabe ao governo promovê-lo. A ausência de um verdadeiro mercado no âmbito educacional, explica Gentili (1996, p. 19), seria responsável pela crise de qualidade que invadiu as instituições escolares. Somente por meio da construção deste mercado dinâmico e flexível, avesso ao sistema escolar rígido e incapaz, se é possível promover os mecanismos fundamentais que garantem a eficácia e a eficiência dos serviços oferecidos: "a competição interna e o desenvolvimento de um sistema de prêmios e castigos com base no mérito e no esforço individual dos atores envolvidos na atividade educacional". Não existe mercado sem concorrência e esta é pré-requisito fundamental para garantir a equidade.

Sem, todavia, obter eco em sua época, em virtude da fase de ouro que vivia a economia do pós-guerra, fundada na política de Bem-Estar Social, a defesa do capital como requisito para a liberdade do indivíduo, passa a ganhar terreno a partir da década de 1970, quando o mundo capitalista avançado se defronta com contínuas e profundas crises econômicas, iniciadas no final de 1960 e, claramente, manifestada nos anos de 1970, quando a crise mundial do petróleo desencadeia a instabilidade econômica capitalista, levando várias economias mundiais a uma profunda recessão, a baixas taxas de crescimento, a altas taxas de inflação, e, consequentemente, a decadência do Estado de Bem-Estar Social. Atribuía-se grande parte a falência econômica do Estado em crise a um esgotamento padrão de regulação econômica (DRAIBE, 1993). Em sua análise, Hayek argumenta que as raízes desta crise conjuntural estavam localizadas do poder excessivo dos sindicatos e do movimento operário, que haviam "corroído as bases de acumulação capitalistas com pressão parasitária para que o Estado aumentasse cada vez mais os gastos sociais" (ANDERSON, 1995, p.10).

Ao final da década de 1970, verifica-se, então, a adesão das políticas neoliberais, compreendidas como alternativa à solução da crise que atravessava o sistema capitalista. A primeira ministra britânica Margaret Thatcher e o presidente americano Ronald Reagan são os primeiros representantes de governo a adotarem o neoliberalismo como orientação de suas políticas e economias. Nesta perspectiva, a concepção de Estado forte é aquela que defende que este deve centrar seus recursos na estabilidade monetária de forma a garantir a flexibilização e a capacidade de concorrência do mercado mundial. Para que seja capaz de garantir isso, o Estado deve reduzir sua intervenção nas questões econômicas e políticas sociais, como também, diminuir gastos desnecessários nesses setores. Inspirados nos argumentos gerais de Friedman, essa será a forma de justificar a desestabilização dos pilares do Welfare State, reduzindo a universalidade e os graus de cobertura de muitos programas sociais, "assistencializando", ou melhor, retirando do campo dos direitos sociais, muitos benefícios e privatizando a produção, a distribuição ou ambas as formas públicas de provisão dos serviços sociais. " $\mathrm{Na}$ base de tal 'redirecionamento' estava a vontade de quebrar a espinha dorsal dos sindicatos e dos movimentos organizados da sociedade" (DRAIBE, 1993, p. 92).

Nos países latino-americanos, submetidos aos rigores dos ajustamentos macroeconômicos e à devastação social que estes vêm provocando, Draibe (1993, p. 92) explica que, "a receita neoliberal pareceria estar contida no conjunto de prescrições de reformas sistêmicas de proteção social, orientadas para a privatização, descentralização, focalização e programas (fundos) sociais de emergência". Apesar do pouco sucesso que teve, devido às restrições impostas pela crise, o modelo chileno passou a ser difundido como o caminho exitoso para a reformulação do papel do Estado na área social ${ }^{1}$. Apoiando-se nesse ideário, novas perspectivas e diretrizes econômicas relativas às políticas 
sociais, como a educação, previdência, entre outros, são estabelecidas para os países em desenvolvimento, como os da América Latina.

\section{As agências internacionais reguladoras e os princípios norteadores para as novas políticas sociais no âmbito da educação}

Para auxiliar na reestruturação e adequação das economias mundiais criou-se a necessidade da intervenção de consultores financeiros, como o Fundo Monetário Internacional (FMI) e o Banco Mundial (BIRD) ${ }^{2}$, para atuarem como agentes mediadores, financiadores e monitoradores dos processos de ajustes estruturais nesses países. Ao mesmo tempo em que estas agências multilaterais dão suporte aos países envolvidos sugerindo alterações, monitorando e intervindo em suas políticas econômicas e sociais, segundo o receituário neoliberal, de modo a tornar sua economia estável e competitiva no contexto mundial e implantar, assim, o "globalismo econômico e social" (OLIVEIRA, 2000) - elas subordinam esta adequação à obtenção de financiamentos. Portanto, a obtenção de novos empréstimos viria somente a partir do cumprimento de tais exigências.

As concessões de financiamentos se traduziriam no poder de intervenção e decisão nas políticas sociais dos países em desenvolvimento. Agências internacionais, como: o BIRD; a Organização das Nações Unidas para Educação, a ciência e a Cultura (UNESCO) e a Comissão Econômica para a América Latina e o Caribe (CEPAL) começam a interferir nas economias mundiais, incentivando a desativação dos programas sociais públicos e impondo ao Estado que se atenha somente em programas de auxílio à pobreza (DRAIBE, 1993), visto que, a redução dessa taxa é considerada imprescindível para uma maior harmonia social.

Sob um discurso humanitário, como explica Oliveira (2000, p. 109), essas agências se laçam "no papel de promotores de serviços sociais básicos para os pobres, como: saúde, planejamento familiar, nutrição e educação primária, com o objetivo de proporcionar maior equidade social" às nações em desenvolvimento. A "equidade", concebida como acesso e universalização da educação, será o princípio orientador, imposto pelas instituições internacionais, que irá se estabelecer hegemonicamente sob as políticas educacionais dos países tutelados pelas agências multilaterais. Este conceito, presente nos discursos que comporão as recomendações neoliberais dos organismos internacionais e os documentos das reformas educacionais, contrapõe-se ao conceito de igualdade, articulando-se ao conceito de justiça, como o reconhecimento da "necessidade de respeitar, e inclusive promover, as diferenças naturais existentes entre as pessoas". O conceito de equidade pauta-se em uma noção promotora das diferenças produtivas entre os indivíduos, enquanto que o conceito de igualdade tende a reproduzir um critério homogeneizador de caráter artificial a serviço de aparentes interesses coletivos que negam as diferenças e, portanto, a própria individualidade das pessoas (GENTILI, 1996, p. 43).

Para a difusão desses preceitos, serão organizados encontros internacionais por parte destas agências, como a Conferência Mundial sobre Educação para Todos, convocada pela UNESCO, pela UNICEF (Fundo das Nações Unidas para a Infância), pelo PNUD (Programa das Nações Unidas para o Desenvolvimento) e pelo Banco Mundial, realizada no ano de 1990, em Jomtien, na Tailânia (UNESCO, 1991). Esta conferência voltou-se para a discussão e a constituição das bases dos Planos Decenais de Educação, compreendido como o instrumento chave para a resolução dos problemas dos países em desenvolvimento, especialmente, em relação à pobreza e à uma melhor distribuição de renda. Como fator precípuo ao desenvolvimento econômico, a educação se torna 
responsabilidade dos governos, os quais deverão se comprometer em mobilizar recursos para o acesso, a permanência e o rendimento dos indivíduos e investir uma porcentagem (pré-determinada pelo Banco Mundial e pelo FMI) de seu PIB para esta finalidade. Caso o país não tenha recursos para promovê-la, recomenda-se o envide de todos os seus esforços, no sentido de adquirirem financiamentos, para assegurá-la; mesmo que, para isso, haja um acirramento da dívida externa. Considera-se que, somente assim, os países alcançarão o desenvolvimento pretendido e necessário nessa nova ordem social (OLIVEIRA, 2000).

A ideia de investimento em educação básica, proposta pelas agências, resgata a Teoria do Capital Humano, desenvolvida a partir do pensamento positivista e liberal clássico, surgida no cerne da ideologia desenvolvimentista. Esta ideologia, muito presente na realidade atual, ao vincular a educação à produtividade, contribui para a difusão do discurso e da crença na eficácia da educação como instrumento de distribuição de renda, equalização social e desenvolvimento econômico (OLIVEIRA, 2000, p. 223). Ela reforça que, o investimento em educação promoveria uma transformação na produtividade e no perfil dos países em desenvolvimento, levando-os a um melhor desempenho econômico e maior competitividade no mercado mundial.

Como explica Oliveira (2000, p. 223), a Teoria do Capital Humano parte da premissa de que o indivíduo na produção é "uma combinação de trabalho físico e educação ou treinamento". Por considerar o indivíduo como "produtor de suas próprias capacidades de produção", denomina "investimento humano o fluxo de despesas que o próprio indivíduo devia efetuar em educação para aumentar a sua produtividade". Dentro desta lógica, o desemprego passa a ser visto como inadequação dessa população às exigências de qualificação colocadas pelo novo padrão produtivo e, não mais, como a consequência do desequilíbrio entre a população economicamente ativa e as ofertas de trabalho no contexto das atuais relações de trabalho e de produção. Com isso, sugere-se a ideia de que "há oferta de trabalho para toda população economicamente ativa e que se trata, portanto, de adaptar a demanda de emprego por parte dos trabalhadores às exigências da oferta" (OLIVEIRA, 2000, p. 225).

Outro aspecto relativo à educação é que ela passa a ser vista como um direito universal, promotora da melhoria das condições da vida da população, já que diminuiria as disparidades de renda e das desigualdades sociais. Também, melhorando-se a qualidade de vida da população, se obteria indivíduos com maior senso crítico e, portanto, mais comprometidos com as transformações sociais. Como argumenta Carnoy, no documento publicado pelo UNICEF, Razões para investir em educação básica (1992, p. 7),

considerando que o bem-estar humano depende, mais do que nunca, da acumulação, processamento e utilização de conhecimentos e que a educação básica é o principal veículo da leitura, da escrita e do cálculo, de geração a geração, esta educação tornou-se um direito universal em todas as sociedades. As pessoas que não podem integrar-se às instituições sociais e economicamente modernas, ao sistema mundial de informações não podem desenvolver sua plena participação política e social sem saber ler, escrever e calcular. Atualmente não se pode garantir os direitos humanos sem garantir também esse direito universal.

Justifica-se, assim, a importância de investimento na educação (fundamental) da mulher, uma vez que sua maior escolarização permitirá, além, da inserção no mercado de trabalho, a interferência e tomada de decisões na educação do filho (higiene, nutrição, saúde, etc.) e no planejamento familiar (controle da natalidade e mortalidade infantil), visto 
que o controle de fertilidade é um pressuposto para qualquer programa de desenvolvimento em função de sua capacidade de auxiliar na contenção da pobreza. Estas agências darão grande ênfase à educação básica, compreendida como: Educação de Jovens e Adultos, Ensino Fundamental e Ensino Médio e recomendarão aos países em desenvolvimento, que se comprometam com a universalização desta. A partir de tais recomendações, a Educação Básica terá como atributo o desenvolvimento no indivíduo das capacidades que se tornaram essenciais ao novo contexto da globalização e das constantes transformações tecnológicas (DELORS, 2006).

Esta premissa guiará o conteúdo do relatório apresentado à UNESCO, pela Comissão Internacional sobre a Educação para o século XXI, redigido por Jacques Delors, entre outros membros: Educação, um tesouro a descobrir. Iniciado em 1993 e concluído em 1996, este relatório, fruto dos encontros internacionais sobre educação, foi adotado como documento base para se pensar a educação. Nele, os objetivos da educação são erigidos sobre quatro pilares, nos quais recomenda-se que o ensino formal deve orientar-se, essencialmente, se não exclusivamente, para o aprender a conhecer e para o aprender $a$ fazer. As duas outras aprendizagens, aprender a viver junto e aprender a ser, constituiriam um prolongamento natural das duas primeiras. A saber,

a) aprender a conhecer e aprender a fazer: são aprendizagens indissociáveis que representam o desenvolvimento da capacidade de adquirir os instrumentos da compreensão para poder agir sobre o meio envolvente. Visam, não tanto, um repertório de saberes, mas o domínio dos instrumentos do conhecimento. Pautam-se na cultura geral, que permite o indivíduo adaptar-se ao trabalho em meio às constantes transformações tecnológicas e à dinâmica da própria organização do trabalho. Em função do processo de aprendizagem do conhecimento nunca está acabado e enriquecer-se com a experiência, ele liga-se cada vez mais ao trabalho e deve realizar-se ao longo de toda a vida, no trabalho, como fora dele. Para isso, a escola deve se tornar o lócus de preparação dos indivíduos para as aprendizagens posteriores, desenvolvendo competências, como: a flexibilidade, a adaptação e o aprender a aprender, de modo a torná-los aptos a enfrentar numerosas experiências e situações geradas no seu contexto local e internacional e atuar, tanto no mercado formal, quanto no informal. A escolha de conteúdos deve voltar-se as necessidades da comunidade e as demandas nacionais e internacionais (global/local), comportando um programa de estudos "cuidadosamente adaptado ao contexto cultural, e tendo em conta as realidades política, nacional e internacional". Também, deve promover a participação da comunidade na escola, de forma a promover a aprendizagem, na prática e ao longo da vida, da democracia e da cidadania. A participação das famílias, dos membros da comunidade, "de sindicalistas, pesquisadores, conselheiros, artistas poetas, que passam algum tempo na escola, para ajudar os alunos a olhar o mundo de maneira diferente e a compreendê-lo a partir de vários pontos de vistas". (DELORS, 2006, p. 57). Não se trata de

ensinar preceitos ou códigos rígidos, acabando por cair na doutrinação. Trata-se sim, de fazer da escola um modelo de prática democrática que leve as crianças a compreender, a partir dos problemas concretos, quais são os seus direitos e deveres, e como o exercício da sua liberdade é limitado pelo exercício de dos direitos e da liberdade dos outros (DELORS, 2006, p. 61).

b) aprender a viver junto: no atual mundo globalizado, caracterizado pelo pluralismo cultural, a educação não deve constituir-se em um filtro, mas "valorizar o pluralismo cultural apresentando-o como fonte de riqueza humana" (DELORS, 2006, p. 
58), levando as pessoas a tomarem consciência das semelhanças e interdependência entre todos os seres humanos e atuar para que os indivíduos possam participar e cooperar uns com os outros em todas as atividades da vida humana em vista de um fim comum. $\mathrm{O}$ estímulo ao trabalho em equipe faz com que cada membro da coletividade assuma as suas responsabilidades em relação aos outros. Isto requer que a escola prepare "cada pessoa para esta participação, mostrando-lhes os seus direitos e deveres, mas também desenvolvendo as suas competências e estimulando o trabalho em equipe na escola" (DELORS, 2006, p. 57).

c) aprender a ser, via que integra as três precedentes. Constitui-se pelo desenvolvimento da personalidade do indivíduo de modo que esteja à altura de agir cada vez com mais capacidade de autonomia, discernimento e responsabilidade pessoal. Para isso a educação atuará para o desenvolvimento de suas potencialidades, tais como, memória, raciocínio, sentido ético, capacidades físicas, aptidão, para comunicar-se etc.

Estes princípios nortearão os Parâmetros Curriculares Nacionais brasileiros, dando o tom para as diretrizes e as reformas educacionais elaborados na década de 1990.

Outra preocupação das agências internacionais diz respeito à redução dos índices relativos ao fracasso e à evasão escolar, uma vez que as primeiras séries do ensino fundamental são às que retém a maior parte dos alunos. O problema educacional brasileiro não seria tanto em termos de quantidade de vagas, mas de sua distribuição (de fluxo escolar). "A repetência sucessiva passa a ser apontada como um desperdício significativo de recursos públicos" (OLIVEIRA, 2000, p. 159), e para uma melhor gestão dos recursos (financiamentos) em educação são propostas políticas que integram: orçamento, avaliação e gestão escolar. Em consequência, há uma descentralização da educação, eximindo o Estado de sua responsabilidade de mantenedor financeiro das escolas. Os municípios assumem os custos, cabendo ao Estado apenas uma complementação àqueles que não conseguirem arcar com seus insumos mínimos. Justifica-se essa ação como sendo um motivo para que a própria comunidade assuma a escola, passando esta a refletir seus interesses.

Dentro dessa lógica, explica Oliveira (2000, p. 164), sugere-se a parceria entre escolas e empresas, como condição para a promoção da qualificação profissional para o mercado de trabalho, prosperidade e competitividade dos mercados. A autora explica que, no Programa de Formação de Parcerias empresa-escola: desenvolvimento e cidadania da Federação das Indústrias de Minas Gerais (FIEMG), o termo "parceria empresa-escola" não remete à possibilidade da primeira suprir, por exemplo, a falta de material da segunda, mas configura-se como "apoio moral", em que os empresários interagem com os estabelecimentos de ensino a partir da intervenção na sua gestão, introduzindo a lógica empresarial no interior da escola como uma espécie de referência sobre gestão e eficiência para a resolução de seus problemas. Não é sem motivo, que a avaliação nacional surge como necessidade para se "desnudar a realidade intrínseca da escola" e averiguar se nestes estabelecimentos vêm se realizando um "bom" trabalho e se os professores são "dedicados". É a ideia da educação como mercadoria, visto que o repasse de recurso é feito mediante custo-aluno (alunos aprovados). O aluno, enquanto mercadoria, passa pelo processo de "controle de qualidade", antes que a escola o entregue a sociedade (ao mercado de trabalho), e a produção da mercadoria, nas quais os professores são responsáveis, é ser supervisionado. Desta forma, cabe à escola, além da preparação dos jovens para um bom desempenho no mercado de trabalho, mantê-los fora da cultura marginalizada da pobreza, pois, 
mesmo que não existam empregos suficientes no mercado formal de trabalho para absorver todos os alunos que concluem o curso básico, essa educação, quando organizada para produzir jovens confiantes e bemsucedidos, pode contribuir para aumentar a produtividade em atividades autônomas informais. Mais educação aumenta a eficiência produtiva dos pequenos empresários (OLIVEIRA, 2000, p. 119).

Ao mesmo tempo em que se toma a educação como condição para a preparação dos jovens - leia-se, da mão-de-obra para o mercado de trabalho -, destaca-se a incapacidade do mercado em absorver toda força de trabalho disponível. A crença na Educação Básica ler, escrever e contar - e sua capacidade em produzir jovens confiantes, seriam a premissa, por si só, suficiente para estes jovens se tornarem pequenos empresários promissores.

No relatório, Delors (2006, p. 66), ao analisar as transformações tecnológicas que vem ocorrendo no mundo, recomenda "que todas as potencialidades contidas nas novas tecnologias da informação e da comunicação sejam postas a serviço da educação e da formação". É a ideia de que a tecnologia romperia as barreiras e a distância em relação à educação, uma vez que a educação a distância alcançaria o que ainda não se consegue e, também, diminuiria consideravelmente os custos relativos à construção e manutenção de uma estrutura concreta (espaço escola), com professores e seus encargos trabalhistas, etc..

$\mathrm{O}$ funcionamento eficiente deste sistema educacional, como previsto e recomendado por Friedman, está subordinado à criação de uma estrutura jurídica legal capaz de consolidá-lo. Não sem motivo, assiste-se, ao longo de toda a década de 1990, uma série de iniciativas e intervenções estatais, em termos de leis, voltadas para a reforma e remodelação do sistema educacional brasileiro. Inclusive a alteração de disposições da Constituição Federal.

\section{Algumas das elaborações e alterações jurídicas para a adaptação e a reforma da Educação brasileira à nova lógica econômica mundial}

Em termos de medidas tomadas pelo Estado brasileiro para imprimir o rumo de tais princípios no âmbito educacional, verificar-se-á uma série de iniciativas no âmbito jurídico $^{3}$ voltadas para a implantação de uma política de compressão de gastos públicos, da redefinição do lugar da União na organização nacional e da transferência de suas responsabilidades, em termos de financiamento e manutenção do ensino, para Estados, Municípios, iniciativas privadas e associações filantrópicas. À União caberá às atribuições de "controle, avaliação, direção e, eventualmente, apoio técnico e financeiro de caráter subsidiário e complementar" (SAVIANI, 2002, p. 82).

Tais pontos podem ser ilustrados por meio de documentos oficiais, como: a Lei 9.131, de 24.11.1995; o Decreto 2.306, de 19.08.1997; a Emenda Constitucional n. 14, de 12 de setembro de 1996 e o Plano Nacional de Educação (1997).

A Lei 9.131, de 24.11.1995, altera as atribuições da União e, em especial, do Conselho Nacional de Educação. De órgão responsável pela coordenação da política nacional, princípio contido na LDB anterior, caberá a União "formular e avaliar a política nacional de educação, zelar pela qualidade do ensino e velar pelo cumprimento das leis que o regem". Esta lei, também: a) extingue o conselho Federal de Educação, instituindo em seu lugar o Conselho Nacional de Educação, composto por duas câmaras, Educação Básica e Educação Superior, com atribuições normativas, deliberativas e de assessoramento ao 
MEC; b) cria dispositivo para a instituição de exames nacionais para os cursos de ensino superior, difundidos pela imprensa pelo nome de provões (SAVIANI, p. 8).

Esperando encontrar certo equilíbrio no desempenho das instituições, de modo a constituir um argumento para se demonstrar a conveniência da redução de investimentos na manutenção de uma rede pública de ensino superior, a divulgação dos primeiros resultados dos exames nacionais, como atesta Saviani (2002), evidenciou, entretanto, o baixo nível, em média, dos cursos de instituições privadas comparativamente ao das instituições públicas de ensino superior, o que fez com que o MEC abrisse uma linha de crédito de 300 milhões de reais para financiar programas de melhoria da qualidade dos cursos das escolas particulares. Esta ação permite ao Estado brasileiro demonstrar que é capaz de realizar com êxito uma lição essencial recomendada pela cartilha neoliberal das agências internacionais: a minimização de sua participação em políticas sociais, evitando a criação de monopólios neste setor, e a complementação da ação do mercado, onde este não é capaz de funcionar de forma eficiente. Assim, premia as instituições particulares deficitárias com financiamentos para a melhoria de seus programas, deixando de investir na educação pública superior.

A subordinação da atual política educacional ao clima aferido pela "referência ao mercado, entendido como campo próprio para a inciativa privada que busca [...] o lucro" (SAVIANI, 2002, p. 13) é também observado no Decreto 2.306, de 19.08.1997, que torna explícito a admissão das instituições educacionais com fins lucrativos, evidenciando os critérios para o tratamento a ser dado às instituições privadas de ensino.

Neste decreto observa-se, também, a introdução da distinção entre "universidades" e "centros universitários", na qual se exime, da segunda, a função de desenvolvimento de pesquisa, tornando-a uma "universidade de segunda classe". Esta alternativa é buscada pelo Governo para "viabilizar a expansão e, por consequência, a democratização da universidade a baixo custo, em contraposição a um pequeno número de centros de excelência, isto é, 'universidades de pesquisa', que concentrariam o grosso dos investimentos públicos, acentuando seu caráter elitista" (SAVIANI, 2002, p. 14).

A ampliação da oferta a partir do aumento de $200 \%$ das vagas públicas e a universalização deste nível de ensino num prazo de dez anos é retomada na proposta apresentada pelo MEC para o Plano Nacional de Educação (1997), sem que, no entanto, seja previsto nenhum investimento para se atingir esta meta. A resposta para esta questão, como demonstra Saviani (2002, p. 83), parece estar no seguinte parágrafo:

A expansão dependerá, portanto, de uma racionalização no uso dos recursos que diminua o gasto aluno nos estabelecimentos públicos, da criação de estabelecimentos voltados mais para o ensino que para a pesquisa, da ampliação do ensino pós-médio e do estabelecimento de parcerias entre a União, o Estado e instituições comunitárias para ampliar, substancialmente, as vagas existentes.

A orientação de ampliar a oferta de ensino, disseminando centros universitários como, escolas superiores dedicadas apenas ao ensino, sem pesquisa institucionalizada, e os cursos pós-secundários, de formação superior de menor duração, também está expressa na meta 12 da Proposta feita pelo MEC para o Plano Nacional de Educação, que prevê o estabelecimento de um amplo sistema de educação à distância utilizando-o, inclusive, para ampliar o ensino semipresencial.

O ensino fundamental é outra frente de atuação do governo federal na formulação e implementação da nova política educacional. Em 12 de setembro de 1996 é aprovada a 
Emenda Constitucional n. 14, que modifica a Constituição Federal e dá outra redação ao Art. 60, do Ato das Disposições Constitucionais Transitórias. Por meio desta, insere-se a "intervenção da União nos Estados em caso de não aplicação, na manutenção e desenvolvimento do ensino, do percentual mínimo da 'receita resultante de impostos estaduais, compreendida a proveniente de transferências", acrescentando-se modificações no sentido de adequar a norma constitucional à orientação da política educacional traduzida, também, na LDB. Por meio do Art. 60 altera-se o Ato das Disposições Constitucionais Transitórias, passando a contribuição dos Estados, distrito Federal e Municípios de 50 para $60 \%$ dos recursos relativos à receita resultante de impostos, compreendida a proveniente de transferências, na manutenção e desenvolvimento do ensino e a redução da contribuição da União de 50 para 30\%. Institui o "Fundo de Manutenção e Desenvolvimento do ensino Fundamental e a Valorização do Magistério" (SAVIANI, 2002, p. 35).

Como explica Saviani (2002, p. 35), o sentido básico da emenda foi o de redefinir o papel do MEC, "que ocupava uma posição lateral na questão relativa ao ensino fundamental de modo a colocá-lo no centro da formulação, implementação, avaliação e controle das políticas voltadas para esse nível de ensino". Para tanto, alterou-se a Constituição no que previa a descentralização política da educação, de modo a conferir legalidade e assegurar à centralização do MEC, a fim de continuar controlando a política educacional relativa ao ensino fundamental e prorrogar ou substituir o Fundo por outro mecanismo considerado conveniente, mesmo após ter passados dez anos de sua vigência. Com base na modificação do Art. 60, o MEC assume o controle da política nacional do ensino obrigatório, sem, no entanto, necessitar arcar com a primazia de sua manutenção. Para isso, ampliou a cota dos Estados, distrito Federal e Municípios (de 50 para 60\%) e reduziu a sua parcela (de 50 para $30 \%$ ) no financiamento do ensino fundamental de forma compulsória, de modo que, caso os Estados e Municípios não operassem de acordo com o mecanismo previsto, perderiam os $15 \%$ dos recursos das respectivas arrecadações que, constitucionalmente, devem destinar à manutenção e ao desenvolvimento do ensino. Em consonância com estes dispositivos, a Emenda Constitucional afirma que os recursos constitutivos do fundo serão distribuídos "entre os Estados e os Municípios, proporcionalmente ao número de alunos nas respectivas redes de ensino fundamental" e que a União complementará os recursos quando "em cada Estado e no Distrito Federal, seu valor por aluno não alcançar o mínimo definido nacionalmente" e em um prazo de cinco anos, a União, os Estados o distrito Federal e os Municípios "ajustarão sua participação no Fundo, 'de forma a garantir um valor por aluno, correspondente a um padrão mínimo de qualidade de ensino, definido nacionalmente" (SAVIANI, 2002, p. 37).

Sobre a política educacional decorrente das medidas previstas pela Emenda Constitucional n. 14, regulamentada um dia após a publicação da nova LDB, por meio da Lei 9.424 de 1996, Saviani (2002, p. 39) observa que, se ela representou uma iniciativa meritória de melhor distribuição de recursos, limitou-se, porém, a "regular a aplicação de recursos já vinculados, não prevendo novas fontes de recurso e, além disso, reduzindo a participação financeira da União". Como resultado,

o custo mínimo por aluno foi fixado em [...] uma cifra irrisória comparada com os valores praticados por países que logram generalizar o acesso e a permanência no ensino fundamental. Trata-se, assim, de um patamar que consagra o estado de miséria da educação nacional, evidenciando a precária vontade política do atual governo no enfrentamento desta questão (SAVIANI, 2002, p. 39). 
No que concerne ao Plano Nacional de Educação proposto pelo MEC, o item relativo ao "Financiamento e Gestão", é previsto a "elevação, na década, através de esforço conjunto da União, dos Estados e dos Municípios e de parcerias com o setor privado, do percentual do PIB aplicado em educação para atingir o mínimo de 6\%" (SAVIANI, 2002, P. 84). Mudança esta, como revela Saviani (2002), excessivamente tímida em face das carências reconhecidas na própria proposta, uma vez que o patamar apresentado registraria no momento a utilização de $4,6 \%$ do PIB, representando este acréscimo um aumento médio de $0,14 \%$ por ano, que se diluiria gradativamente ao longo dos dez anos de vigência da proposta do PNE, sem nenhum impacto efetivo sobre o estado da educação nacional.

Também, cabe ressaltar que, a meta de n. 19, proposta como primeira versão do Plano, recomendava que se estimulasse "a participação da comunidade na manutenção física e na melhoria do funcionamento das escolas, incentivando o trabalho voluntário" (SAVIANI, 2002, p. 82).

Outro grau de descompromisso da União, apontado por Saviani (2002, p. 85), é verificado na diferença relativa ao número de metas indicadas no Plano, que dependeria do esforço conjunto dos Estados e Municípios com a União e os que indicariam àquelas que caberiam prioritariamente à União. A proposta do Plano enunciaria 167 metas das quais 59 seriam de responsabilidade dos Estados e Municípios em colaboração com a União, enquanto apenas 16 caberiam exclusivamente à União. Numa análise de cunho qualitativo, o autor observa que, as metas admitidas pela União no PNE se restringiriam, via de regra, em atividades voltadas para a elaboração de documentos, a definição de diretrizes, o estabelecimento de normas e a organização de sistema de informações, fugindo a esta regra apenas a meta relativa à Educação Profissional, que se refere à multiplicação dos CEFETS. Não se trataria, neste caso, de "qualquer investimento novo, mas da transformação das Escolas Técnicas Federais". No que diz respeito ao Ensino Superior, área de responsabilidade prioritária da União, Saviani (2002) destaca que nenhuma das metas foi assinalada como: "exige colaboração da União" ou "depende da iniciativa da União".

A repercussão causada por este documento, fez com que dezembro de 1997 surgisse, sob a forma de versão preliminar para discussão interna, outro documento do MEC sobre o Plano Nacional de Educação. Em seu texto, já não aparecem às considerações preliminares sobre metas propostas, mas seu enunciado. Em comparação ao documento anterior, Saviani (2002) explica que se verificam algumas alterações da redação e o aumento de metas, (de 167 para 245). A versão que será encaminhada ao Congresso Nacional, em fevereiro de 1998, conterá 248 metas, sendo 33 relativas à cooperação e responsabilidade da União e 88 baseada no esforço conjunto dos Estados e Municípios com a União. Este aumento, explica o autor, deveu-se a um maior detalhamento das metas, embora se tenha mantido a orientação geral presidida pelo documento anterior. Dentre as metas acrescentadas, está a de número 3, referente ao ensino superior, que prevê a esfera Federal assegurar a criação de um Fundo de Manutenção do Ensino superior, destinados à manutenção e expansão da rede de instituições federais. No entanto, não se especifica de onde viriam os recursos que comporiam este fundo.

Outra mudança referente ao ensino superior na passagem da primeira para a última versão do Plano do MEC, apontada por Saviani (2002), é a alteração da legenda. Substituise, na versão oficial, a legenda cujas metas caberiam "prioritariamente a União" por "metas que exigem a colaboração da União com outros setores governamentais e não governamentais", de modo a assegurar a política da contenção financeira, uma vez que o que se exige da União é a colaboração com outros setores governamentais e nãogovernamentais, e não a sua responsabilidade prioritária na viabilização das metas que são 
de sua responsabilidade. Na verdade, "o plano assume o significado estrito de forma de aplicação de determinado montante de recursos financeiros" (SAVIANI, 2002, p. 76).

\section{Conclusão}

Os documentos e análises apresentados ao longo do texto revelam os meios pelos quais a Teoria de Estado Neoliberal influiu sobre as políticas sociais, em especial, a educação. Os pressupostos desta abordagem teórica adentraram o cenário brasileiro a partir do governo de Fernando Collor de Melo, sendo reforçadas pelos governos seguintes de Itamar Franco e Fernando Henrique Cardoso, na década de 1990, quando, em nome da "globalização" e da "modernização", o Brasil abre o mercado nacional ao capital financeiro estrangeiro, passando a ser tutelado pelas agências internacionais multilaterais, que subordinam os financiamentos aos países em desenvolvimento à adequação de suas políticas econômicas e sociais aos princípios neoliberais. Não por acaso, esta década se caracteriza por inúmeras reformas do Estado brasileiro e de suas instituições, voltadas à criação de um sistema jurídico de modo a conferir legalidade a tais pressupostos e dar encaminhamentos à implantação e à consolidação deste modelo econômico. Neste período, verificam-se medidas dirigidas para o estímulo a política de privatização, o enfraquecimento das centrais sindicais, a precarização e intensificação do trabalho, o corte em gastos com políticas sociais, a descentralização e a redução da intervenção do Estado em áreas sociais em função da priorização do livre mercado e da empresa privada.

As consequências desta diretriz político-econômica no âmbito educacional incidiram tanto na esfera ideológica, com a elaboração de documentos norteadores dos rumos da nova educação "globalizada", como em termos legais, onde foi preciso construir uma estrutura jurídica alterando-se a própria Constituição do país para imprimir os fundamentos do modelo neoliberal.

No que diz respeito aos discursos teórico-ideológicos propagados pelas agências multinacionais para a adequação das políticas educacionais dos países em desenvolvimento à nova ordem mundial, ou melhor, a nova lógica de exploração capitalista, a Educação Básica (leia-se: ler, escrever e contar) é alçada à condição de salvadora da Pátria. Vista como direito universal, lhe é atribuído o papel de desenvolvimento de melhores condições de vida da população, diminuição das desigualdades sociais e promoção do senso crítico nos indivíduos para que possam se tornar capazes de atuar na nova sociedade em constante transformação e conhecer seus direitos e deveres. Assegurada a Educação Básica pelo Estado, ao indivíduo caberia a "própria responsabilidade com relação a seu próprio destino" (FRIEDMAN, 1988, p. 11), isto é, o investimento em sua educação para que possa aumentar sua capacidade produtividade no mercado de trabalho. Mesmo, sendo o desenvolvimento do senso crítico apontado como importante aspecto da educação em tais documentos, o princípio educativo se pautará pelo desenvolvimento de competências. Não se fala mais no ensino sólido de conteúdos, mas na promoção de competências necessárias às demandas do mercado globalizado, que exige capacidades como aprender a conhecer, aprender a fazer, aprender a viver junto, aprender a ser, regidos segundo o princípio do aprender a aprender ao longo de toda a vida do indivíduo. Diretrizes que são explicadas em função do conhecimento não se constituir em algo acabado em si, mas estar em constante mudança, devendo, então, ser assimilado por meio de experiências provindas do cotidiano e do trabalho e por conteúdos generalistas fornecidos pela escola, capazes de garantir maior flexibilidade e adaptação dos indivíduos frente ao novo mundo de intensas transformações. É a educação do homem integral - viabilizada pela aprendizagem dos 
fundamentos teóricos humanísticos e da ciência, que permitem o indivíduo, enquanto um ser crítico, desvelar e compreender o mundo para além da aparência - cedendo lugar ao pragmatismo da realidade imediata, a educação minimizada (ler, escrever e contar), a formação do consumidor e, enfim, ao mascaramento das desigualdades sociais promovidas pela dinâmica do próprio sistema capitalista de acumulação de riqueza.

A lógica de mercado adentra a Escola: parceiras que devem ser feitas entre empresas e escolas de modo a garantir que o aluno (a mercadoria) passe pelo controle de qualidade exigido pelas necessidades mutantes do mercado de trabalho. Ao professor é dada a formação rápida e necessária para forjar o produto final, ao mesmo tempo, em que dispositivos são criados para controlar e aferir seu trabalho individual e de toda a instituição escolar. Instala-se o frenesi das avaliações. Condiciona-se a eficiência do processo de produção da mercadoria (avaliação do trabalho do professor) e seu resultado (avaliação do aluno) ao repasse de recursos financeiros por parte do Estado. Não deve haver desperdício de recursos, por isso não se reprova. Dissimula-se o fracasso escolar por meio da adoção de uma nova fórmula para o enfrentamento do problema: os ciclos de aprendizagem.

No âmbito das ações efetivas para a consolidação dos ideais neoliberais, reformas são empreendidas a fim de imprimir um novo caráter ao Estado. Para evitar o monopólio e os ideais coletivistas, destruidores do direito político dos indivíduos, este se retira cada vez mais da esfera dos direitos sociais, passando a promover a concorrência - compreendida como o único meio de utilização das forças espontâneas da sociedade e garantir a troca voluntária - do livre mercado da empresa privada e envidar todos os seus esforços para a diminuição de gastos desnecessários. Mesmo que isto signifique por abaixo os direitos sociais historicamente conquistados.

O Estado brasileiro realiza com êxito a lição aprendida na cartilha neoliberal: cria um arcabouço jurídico capaz de dar legalidade a destruição dos direitos civis e políticos do cidadão, garantindo a prevalência do livre mercado e da iniciativa privada. Sua primeira iniciativa é redefinir seu lugar nesta nova organização. Institui-se como o árbitro do jogo. Centraliza em suas mãos a atribuição de formular, implementar, avaliar e controlar as políticas educacionais nacionais, sem, no entanto, necessitar arcar com a primazia de sua manutenção. Em nome da descentralização do poder do Estado, transfere-se o financiamento dos recursos para a promoção e manutenção da instrução pública, ampliando-se a participação dos Estados e Municípios e reduzindo-se a participação financeira da União. Ao Estado é atribuído à complementação àqueles, Estados e Municípios, que não conseguirem arcar com seus insumos mínimos. Ação esta, que serve de justificativa para a assunção da escola pela própria comunidade, que passa a refletir seus interesses. A comunidade é chamada a participar e contribuir com a manutenção física e a melhoria do funcionamento das escolas. Insere-se a cultura do voluntariado e se precariza, ainda mais, o trabalho e a profissão docente, que se veem diante do paradoxo constituído por uma formação baseada em cursos aligeirados e no esvaziamento de conteúdos necessários à sua prática e na condição que lhe é atribuída de fomentador do espírito crítico dos alunos. Se qualquer indivíduo sem formação específica é capaz de fazer o trabalho docente, não há, também, a necessidade de investimentos em uma sólida formação acadêmica. Em consequência, a criação de centros acadêmicos, influenciado pela epistemologia prática, e cursos à distância são priorizados como forma de garantir a universalização da educação superior a baixo custo, uma vez que não precisam investir em pesquisas, e a utilização de tecnologia, além de romper com a barreira da distância enfrentada pela educação, diminui consideravelmente os gastos com manutenção de espaço físico, salários dos professores, encargos trabalhistas etc.. 
Na matriz econômica, política, teórica e ideológica do Estado neoliberal, prevalece, sempre, a política da contenção financeira e a equação entre qualidade e investimento, prevista pelo próprio Friedman (1988), é uma realidade cada vez mais longe. As contradições da dinâmica do sistema capitalista e o mito forjado sobre a liberdade individual e a garantia de direitos políticos erige-se fetichizando as relações sociais de produção e a mercantilização do processo mundial da economia. Estimula-se a crença da eliminação do caráter elitista de nosso sistema educacional, bem como, na igualdade de condições dos países em desenvolvimento e dos países desenvolvidos no jogo do capitalismo financeiro. Mitos que, talvez, expliquem parte do grande sucesso do neoliberalismo: em nome das bandeiras universais de liberdade e da individualidade, fomenta-se a condição de alienação dos indivíduos, para que continuem a olhar para superficialidade da realidade objetiva, sem que sejam capazes de enxergar para além das aparências. Com isto, mantêm-se os privilégios da classe dominante e a exploração financeira capitalista dos países desenvolvidos.

\section{Referências Bibliográficas}

ANDERSON, Perry. Balanço do neoliberalismo. In: SADER, Emir; GENTILLI, Pablo. Pós-neoliberalismo: as políticas sociais e o Estado democrático. Rio de Janeiro: Paz e Terra, 1995, p. 9 - 23.

CARNOY, Martin. Razões para investir em educação básica. New York: UNICEF, 1992.

DELORS, Jacques. Educação, um tesouro a descobrir: relatório para a UNESCO da Comissão Internacional sobre a Educação para o século XXI. São Paulo: Cortez, 1996.

DRAIBE, Sônia M. As políticas sociais e o neoliberalismo: reflexões suscitadas pelas experiências latino-americanas. Revista Usp, São Paulo, 1993, n. 17, p. 86 - 101, mar./maio, 1993. Disponível em: < http://www.revistas.usp.br/revusp/article/view/25959>. Acesso em: 16.01.1914.

FRIEDMAN, Milton. Capitalismo e liberdade. São Paulo: Nova Cultural, 1988. (Os economistas).

GENTILI, Pablo. Neoliberalismo e educação: manual do usuário. In: SILVA, Thomaz Tadeu; GENTILI, Pablo. Escola S. A.: quem ganha e quem perde no mercado educacional do neoliberalismo. Brasília: CNTE, 1996, p. 9 - 49.

HARVEY, David. O neoliberalismo: história e implicações. São Paulo: Edições Loyola, 2013.

HAYEK, Friedrich August Von. O caminho da servidão. Campinas: Vide Editorial, 2013.

OLIVEIRA, Dalila Andrade. Educação básica: gestão do trabalho e da pobreza.

Petrópolis: Vozes, 2000.

SAVIANI, Demerval. Da nova LDB ao novo Plano Nacional de Educação: por uma outra política educacional. Campinas: Autores Associados, 2002.

SILVA Jr., João dos Reis. O papel político da municipalização na construção dos novos trações da sociedade civil na década de 1990. In: MARTINS, Angel amaria et al. 
Descentralização do Estado e municipalização do ensino: problemas e perspectivas. Rio de Janeiro: DP\&A, 2004.

UNESCO. Declaração mundial sobre educação para todos: satisfação das necessidades básicas de aprendizagem. Jomtien, 1991

\footnotetext{
${ }^{1}$ Sobre a experiência chilena ver Harvey (2013) e Anderson (1995).

2 Órgão ligado a ONU, pensado como fundo de investimento para a reconstrução dos países que tiveram suas economias devastadas pela Segunda Guerra Mundial e, também, para auxiliar países da América Latina, que viviam em seu desenvolvimento o dilema entre a modernização e o subdesenvolvimento.

${ }^{3}$ Como as leis que anteciparam a Lei de Diretrizes e Base (LDB), a própria LDB (1993), o Plano Decenal de Educação (PDE - 1993) e a proposta apresentada pelo MEC para o estabelecimento de objetivos e metas do Plano Nacional de Educação (PNE - 1997) - documento voltado à identificação implementação das prioridades relativas às regulamentações previstas na LDB (1996) e no PDE.
}

Recebido: abril-14 Aprovado: agosto-15 